\title{
THE PIANO'S SOUND APPERCEPTION IN HAVASI BALÁZS'S COMPOSITIONS, WITH SOME REMARKS FROM ALFRED WHITEHEAD AND THEODORE ZIOLKOWSKI
}

\author{
MARIA-ROXANA BISCHIN ${ }^{1}$ \\ University of Bucharest \\ mariaartspy16@yahoo.com
}

Motto:

"To understand the philosophy of the music, one must not understand the philosophy, but the music."

\begin{abstract}
In a world full of suffering, the only thing that remains is music. Due to the present situation of the music in our lives and problems of the research in the field of philosophy of the music, it becomes a special priority for us to try to investigate the new sense of the contemporary music. The nature, the sensitive part of our feelings and the perceptions, have made possible the fact that music can be lived. For a deeply examination of the philosophy of Havasi's symphonies, we should ask ourselves if the essence of the sound becomes a part of our 'lived world' and if establishes Heidegger's 'worldliness of the world'.

Meanwhile, it is an important priority for a philosopher to show how the tradition can be break, even in a phenomenological field of study. Culture helps us to understand the spiritual functions of the music in our lives. We will try to demonstrate in this article why the music of Havasi Balázs is a philosophy of the lived "given facts" and a direct "experience" for the world. He establishes a different classical-contemporary aesthetic in music and opens a field of research between the aesthetic category of the classic and lived perception. At last, but not least, Havasi remains the most romantic pianist from our times. Due to him, we can return sometimes to innocence and connect ourselves with the inner-lived world through sounds.
\end{abstract}

Keywords: Havasi Balázs; piano; perception; phenomenology of the music; apperception; conscience; symbolism; classicism;

\footnotetext{
${ }^{1}$ Maria-Roxana Bischin, University of Bucharest, mariaartspy16@yahoo.com.

${ }^{2}$ Peter Kivy, New Essays on Musical Understanding, Clarendon Press, Oxford, 2001, p. 92.
} 


\section{Introduction to classicism in Havasi's case}

Havasi Balázs is a composer of classical-contemporary music. Due to his studies on the Franz Liszt Academy and due to the idea that his country is rich in some great composers as Béla Bartók, we can say that his spiritual and cultural patterns of his music were very well previewed. Each cultural function of his compositions begins with a spiritual function. We can say that in his songs exists the synchronism between the tradition and the aesthetic category of the 'contemporary'. For example, Theodore Theodore Ziolkowski defines classicism as an aesthetic attitude in front of life. What we perceive as classic is what the perception reported to me in my conscience as a affirmation of "this building is classic". Why a building or a song is classic? Because they already have some properties borrowed from classicism itself. But different from the classicism of $17^{\text {th }}-18^{\text {th }}$ centuries, there is a classicism in $20^{\text {th }}$ centuries which maintains nowadays, as Ziolkowski observed:

Classicism is sometimes used to designate two separate aesthetic phenomena of the early twentieth century. First, its writers and artists often took themes from Greek and Roman history and mythology as their subjects, as did Joyce when he borrowed the tale of Odysseus as the prefigurative pattern for his Ulysses (1922). Second, writers, artists, and musicians sought to achieve in their own works the form and the values of simplicity and order that epitomized ancient classicism, as when the purity of line evident in the works of Picasso's so-called classical period in the 1920s is said to correspond to the elegant forms of Greek sculpture. ${ }^{3}$

We think classicism is an atemporal condition of the existence of the beautiful as a value of the naturality of all the things around us. As we can see from the book of Theodore Ziolkowski, classicism is something which was present all the time during the centuries. A classicism is present nowadays, in 21th century, because we still are looking for the principles of the Beautiful around us. The World itself can not exist if we do not have a consistent value in which our judgement can believe. To believe means to understand We must define first the aesthetic category of the 'classic'. What is 'classic'? In Embreé Lester's phenomenology ${ }^{4}$, 'classic' can be a painting of Van Gogh associated to the idea to drink a coffee in front of it. This is a classic feeling of what we feel and of what we perceive in our 'givens'. But, also classic can be the idea associated with the era of the classicism. But some things in the romanticism were classical too, or in Ancient Greece, was the period of the classicism. I think that classic is rather a feeling of the moral feelings and values. Classicism exists in our modernity too and it is a different state of perceiving from other manifestations of the aesthetic forms in cinema, theatre, performance, ballet or even music. Havasi manipulates the idea of the classicism of the feelings very well due to his inspiration of the moral values, themes and traditions. In the gallery of the musical geniuses we find composers who had generated the interest of the musicologists and philosophers. About Wagner or

\footnotetext{
${ }^{3}$ Theodore Ziolkowski, Classicism of the Twenties. Art, Musice Literature, Chicago Press, Chicago, 2015, p. 7.

${ }^{4}$ See Hans Reiner Sepp, Lester Embree (ed.), Handbook of Phenomenological Aesthetics, Springer, Charles University Prague \& Florida Atlantic University, 2010, p. 354.
} 
Beethoven has been written a huge library. From our contemporan perspective, we can hope that for Havasi it will be written a library too.

A song is not just a simple song, it is also an instrument of experienced knowledge of other cultures. Starting with the similarities between the music of the Richard Wagner and Havasi's music, we observe that the romanticism takes his value-fundaments from classicism. In some songs, as "Daisy's Secret", "Storm", "The Road", "The Duel", "Sunrise" we can observe some feelings from the romanticism. The static perfection of the classicism is associated with the "nostalgia" from the romanticism to such an extent that they want to become a "modern perfection". But this perfection of the modernity becomes a dialectical stage for the limits for the romanticism, and this phenomenon was named by Edgar Papu "homeostasia as a stage of the continuity of one to the other one", as a continuity of the classicism through romanticism and viceversa. ${ }^{7}$ The functionality of the lived-worldliness of the Havasi's songs comes from a romantic existence: "The first case gives rise to emotional enthusiasm; the other to the inspiration to the genius."

I will try in this article to analyse the philosophy behind the Havasi's music and why he remains a contemporan, but in a classic-romantic style. The songs let us to follow him from the beginning with his first contact with first piano tile until his crescendo in a Corinthian musical style. His music is an acoustic one, without spoken lyrics. Due to the scenography and designs we have in front of our eyes the best synesthezia- visual images united through sounds, experiences united through sounds and things united to the judgements through sounds. That is the reason why we can distinguish between the perception and apperception of sound. The essential datum of the sound associates the judge with the perception.

\section{The scenography as a creator of perception}

We can see in the havasian decorations several objects: candles, piano, lights, fire, instruments such as violin, viola or cello, his shirts, streets, trees in blossom - all these objects are broken from the realm of reality. The apparent 'material' objects will play an important role in creating the decorations for the scene. But they will have visual effects on the conscience of the viewer in the room. As such, these objects will create the scenography of a new framework - the transcendental framework of real objects in the plane of the conscience. The physical-objects perceived by the viewer in the room will change their meanings when they move on into the consciousness plane.

\footnotetext{
${ }^{5}$ I will mention some of the songs of Havasi Balázs, in Album Arena Show 2017, Hungarian Radio Studio no.6, Budapest, 2017: "Daisy's Secret", "The Road", "Faena”, "The Duel", "Storm", "Sunrise", "Hypnotic".

${ }^{6}$ Edgar Papu, Despre stiluri [On Styles], Romanian edition, Eminescu Publishing, Bucharest, 1986, p. 301.

${ }^{7}$ Loc. cit., for the argumentation of the idea, see the syntagma "static classical perfection".

${ }^{8}$ Peter le Huray; Day, James; Music and the Aesthetics in the Eighteenth and Early-Nineteenth Century, Cambridge University Press, Cambridge 1981, [reedited in 1988], p. 106.
} 
Havasi had established in his songs a symbolism of the perception because through the thems aborted as life, the renaissance of the soul, happiness, sadness. The more impotant roel plays the design of the scenography. The performance methodologies from nowadays show us that exist a permanent connection between "the interactions of current epistemologies and ontologies". The detailed scenography with elements of classicism is the which one which creates the symbolically referentiality framework. The symbolical-images of life are limited by their own 'Becoming', but they set up existential-ontological symbols. We can talk of the existence of a parnasian symbolism in the songs of the Havasi. Beyond this symbolism, he touches the idea of the apperception through sound, because the sounds open the reflexivity of the hidden worldliness. The symbolism of the Havasi's songs is a creator of an open-worldliness of apperceptions: "There are, however, three original sources (capacities or faculties of the soul), which contain the conditions of the possibility of all experience, and cannot themselves be derived from any other faculty of the mind, namely sense, imagination, and apperception. On these are grounded (1) the synopsis of the manifold a priori through sense; (2) the synthesis of this manifold through the imagination; finally (3) the unity of this synthesis through original apperception. In addition to their empirical use, all of these faculties have a transcendental one, which is concerned solely with form, and which is possible a priori. We have discussed this with regard to the senses in the first part above, however, we will now attempt to understand the nature of the two other ones." ${ }^{10}$ The conscience will associate the capacities of the soul with the sounds layed by Havasi. For example, in the song Spring (The Chinese Tree) ${ }^{11}$ we have all the possibilities of the datum of the experience: imagination, the sense of the song and the sense of the life, the synthesis between my imagination and my perception is possible becuase my judge unifies the natural things with the conventional things of the human-worldliness. The Unbending Chinese Tree begins with a fascinating language which is made for us due to the Havasi hands: It begins as a modulated counterpointed scream with calming effects, as a question about what Being can $b e$. The association between the tree and the being is perceptible according to the Bergsonian theories, but even so, away from the phenomenological way of how things works in Havasi's symphonies, there is a metaphorical and poetic way in which they function. I think rather, we can understand the music by looking at it through its poetic side, and then through its side composed by the phenomena which happen in conscience. In other songs, Terra Rosa ${ }^{12}$, the apperception

\footnotetext{
${ }^{9}$ Baz Kershaw; Helen Nicholson; “Introduction: Doing Methods creatively", in book Research Methods in Theatre and Performance, edited by Baz Kershaw and Helen Nicholson, Edinburgh University Press, Edinburg, 1988, p. 4.

${ }^{10}$ Immanuel Kant, The Critique of the Pure Reason, translated and edited by Paul Guyer an Allan W. Wood, Cambridge University Press \& Yale University Press, Pennsylvania and Yale, 1998, p. 225.

${ }^{11}$ Balázs, Havasi, "Spring. Cultural Bridge Symphony", in Album Symphonic Arena-Show 2014, Budapest, 2014, length 4:56.

${ }^{12}$ Idem, "Terra Rosa", in Album Havasi-Red, EMI Music Publishing, Budapest, 2008, length 4:23.
} 
fundaments itself due to the multiple datum of the sounds transmited through the violin in a tall register and the piano in a mezzo register, this song not only makes us feel something, but our perception is transportated to another a priori experience. In both cases, we can not choose to understand only one of the nature. There are two types of the natures: the nature of the datum-experience and the nature of the world. To justify why is the apperception of Havasi's is a simbolistic register, is of what I just demonstrate before: "The complexity of the musical symbolism does not end with the various persons concerned; it exists in many symbols themselves, for music invlves not only auditory symbols-melody, harmony, rhythm, tone-color, structure, dynamics, an so one- but visual ones also, in its instruments and performersand notations. Many of these symbols are as extended as a whole musical work; others are brief-painting. The same considerable variety is also presented by the entities that may be symbolized: physical objects and motions, feelings and moods, abstract ideas and conceptions, even music itself, both as physical events and as an emotional experience". ${ }^{13}$

We see that Havasi unifies these two experiences. He unifies the physical world (which includes the piano, the spectators, his hands, the nature) with the emotional-perceptive experience. In his performances he uses a multitude of tehcniques of decorating the stage, a multitude of the musical techniques all concerned to produce strong emotional effects on the spectator's perception. Finally, due to his unique musical symbolism, correlated to the function of the ornamentation and improvisation very different from others, he remains an authentic value for the contemporary acoustic music. Understanding the music means to pass from the "I think" to "I do" ${ }^{14}$. That means to set up the sound in the real plane of the man existence.

\section{The Chinese Trees and the axiomatic unity between sense and perception}

In contrast to other categories of art, classicism has not fallen. On contrary, he rebels, because it is a 'natural condition' of the human being, just like the Baroque. They are not just categories in the classification of artistic forms, but they are forms of manifestation of life in nature - from the way the trees look to the way we hold the fork in our hand. The same phenomenon also happens in music, and Havasi, in his appearances on scene, admits that the 'classicism' formatted his entire career and his way of thinking on life. What we see in Havasi's creations, are the 'natural' situations of the being unaffected yet by it's own de-construction.

It is known fact that a culture without borders is possible through music. And a life with borders can be free only when the 'classic' works in carving its 'natural' forms. In Whitehead we have a double-loop executed between sense and perception. We think that in music, exists a unity between senses and perceptions. In fact, the sounds are the vehicle of this type of unity:

\footnotetext{
${ }^{13}$ Arthur E. Lippman, "Symbolism in Music", in The Musical Quarterly 39 (4), Oxford University Press, 1953, p. 554.

${ }^{14}$ Peter Kivy, op. cit., p. 156.
} 
"The question as to whether sense-perception involves thought is largely verbal. If sense-perception involves a cognition of individuality abstracted from the actual position of the entity as a factor in fact, then indoubtedly does involved thought. But if it is conceived as sense-awareness of a factor in fact competent to evoke emotion and purposeful action without further cognition, then it does not involve thought". ${ }^{15}$

Anthropologically thinking, the sounds were a kind of language which did not had the necessity of the process named 'translation'. That is the reason why the acoustic-piano music has no necessity to translate the sounds. We can instead try an acoustic-translation of the perceptions, namely to demonstrate how the sound can translate a perception because of the mechanisms of our conscience. In the Spring Wind. Cultural Bridge Symphony, ${ }^{16}$ Havasi's opens in anthropological dimension of the music are based on the function of the myth: "Myths are values of representation, that is, images co-adapted to the structure of value. Modern classics see in simple myths poetical images, objects of representation." ${ }^{17}$ The acoustic similarities between the Spring and The Unbending Chinese Tree were created with the purpose to have a unity of one cultural world presented: the Chineseone but with European classical accents. This trans-positionality demonstrates that different acoustic experiences can create different apperceptions in our judgement of the worldliness. ${ }^{18}$ "That nature should be direct itself according to our subjective ground of apperception, indeed in regard to its lawfulness even depend on this, may well sound quite contradictory and strange. But if one considers that this nature is nothing in itself but a sum of appearances, hence not a thing in itself but merely a multitude of presentations of the mind, then one will not be astonished to see that unity on account of which alone it can be called object a of all possible experience"19.

The Spring and the Chinese Tree represented through sounds creates an intersensoriality between the apperception and the lived- experience. Nature is more than a sum of datums and appereances, if we hadn't the unity with the inner personal world and feelings, the nature and object represented in our exteriroity will be just objects. If we want liek them to capture senses, then they will need that their senses to be understand, and this is possible only through apperception. From what we observe, it is at Havasi's a special technique to make it possible. He must have placed himself in the place of what the spectator can perceive and understand, and only then has his work enlarged even more. It is, as we say, that he has put himself in the situation of thinking with the mind the cultural horizon of the spectator who

\footnotetext{
${ }^{15}$ Alfred North Whitehead, The Concept of Nature, Cambridge University Press, Cambridge, 1920, p. 14.

${ }^{16}$ Havasi, "Spring Wind. Cultural Bridge Symphony" in op. cit.

${ }^{17}$ Tudor Vianu, Studii de filozofia culturii [Studies on Philosophy of Culture], Romanian edition, Eminescu Publishing, Bucharest,1982, p. 40.

${ }^{18}$ Havasi Balázs \& Yunnan Province Art Group, "The Unbending Chinese Tree", in Album Symphonic II, Havasi Entertainment Ltd, Budapeste, 2013 , length 5:01, available on https:// www.youtube.com/watch?v=Mk4a6-7ojvw, accessed 13 august 2018.

${ }^{19}$ Kant, op.cit., p. 236.
} 
has listened to his song. Taking these perceptions from nature, he worked them out and gave them a more visual-like form using sound techniques. His sounds thus have an imaginative substantiality capable of rediscovering mythical archetypes.

\section{The «Etude's no.1 to no.13» or the Mirror of the Classicism}

Having the hypothesis from 1, 2 and 3 we can demonstrate that the aesthetic sphere of classicism in Havasi's creation is one of the apperception of the experiencelived-worlds. As example, the series named «Etudes no.1-no. $13 »^{20}$ opens us the visual form and the acoustic formula of the manifestation of classicism. In Etude no. 1 we see that Havasi had exercised a neo-classical form of the Ernesto Cortazar's Silence ${ }^{21}$ dedicated to Ludwig van Beethoven. The similarities are obvious, but I think that is necessary to maintain the tradition and to give her a new form of expressivity. The contents remain the same, only the perception changes through the passages of the piano tiles. Can be the acoustic perception 'classic' too? Definitely yes, because when I listen the "Etude no.1" in my listener hypostasis, I will think to the Richard Wagner's songs, Franz Liszt, Béla Bartók or I will think to the Greek moral values named Aréthe. In the classic category of the Aréthe are involved the Beautyness, the Goddness, the Justice, the Freedom, the Love.

How can I know that in the music of Havasi, I as a listener am I exposed in front of the Aréthe-groups? I know because of my-lived-a priori-experience and because there is something which thinks on the idea of the judgement of the judging the idea of 'Beautiful'. Is in here the presence of the judicative of the 'Beautiful', a realm that Havasi had touched through sounds. It is set up the unity between the sounds and the judicative. My judge connected with the exterior world is itself exposed, because the Becoming tries to open the Becoming, as Heidegger said. And because the sound is delivered to us: "As a matter of fact it is difficult to describe even the pure sound, and we do not ordinarily do so, because it is not what we commonly hear. [From the standpoint of sheer sound] we always hear more. We hear the flying bird [...]".22 But, due to the imagistic and visual effects, and soundly effects too, we hear also the trees how they whispering in the dark, even if we don't see and touch them as silk: "We touch velvet, silk; we see them directly as this and that kind of essent, the one different from the other. Wherein lies and wherein consists being?"23

Why do we hear every time much more? Is there a psychological effect of the sound to our conscience? But we do not want to leave the field of the phenomenology and natural philosophy. I think we hear much more every time, because the personal judge will receive the sounds, will amplifies them in those

\footnotetext{
${ }^{20}$ Havasi Balázs, "Etude no.1-no.13", in Album Solo Piano Etudes no.1-no.13, Havasi Entertainment Ltd,Budapest, 2014.

${ }^{21}$ Ernesto Cortazar, "Beethoven Silence", in Just for You, 2009, length 9:54. Other source is https://www.youtube.com/watch?v=YFD2PPAqNbw , accessed 13 august 2018, length 9:56.

${ }_{22}$ Martin Heidegger, An Introduction to Metaphysics, translated by Ralph Manheim, M.B. Publishers Private Limited, Delhi, 1999, 2005, p. 34.

${ }^{23}$ Loc. cit.
} 
structures and contents of the conscience, and give them a temporal value which makes them to become a "conscience-expression" ${ }^{24}$. Which makes the difference is the intentionality of the experience. We can ask ourselves what has a 'Being' character? ${ }^{25}$. I think the Being character is in every piano tile touched by Havasi hand. This his co-ordination between the hands, body, and creator's mind develops a double ontological circle: that of the Becoming of the creator and his complete perfection through his music, and that of the Becoming of the spectator flooded by all effects produced by sounds.

Paul Kivy mentioned talks about the arousal theory of the music expressiveness ${ }^{26}$ which is necessary to understand how Being function relating to music. Musiccan reveal in us negative emotions, but in the case of Havasi's music we only have positive emotions as beautiful, peace and good.

Unfortunately, or fortunately, music is not like the verbal language. Then how do we understand it? Do we just understand it to fall aside what we know about what I've read or heard? Do we understand it because we put aside all mathematical and physics calculations? How do we understand this music that produces something in us? Sounds awakens us to other reality, completely different from the one around us - our reality of in quality of the beings who are here to understand something. And then, the process of our communication and our understanding of music is possible because the sound creates a complete unity between the listener's conscience and his judgment, which, unlike other languages, must no longer manifests verbally, but merely soundly.

\section{Havasi as a creator of two-sound-worlds: the sound-worldliness and the sound-world}

We may introduce the distinction between two different sound-worlds: the sound-worldliness and the sound-world and transform them in a double hermeneutic: sound- of- worldlinesses. Why is so important to put this "worldliness" on plural? Because this "worldliness" brings all the other worlds together. Rarely a musician can touch this type of the haptic and lived unity of the lived-lives. As Husserl said, the objectivity is which separates the worlds, but the transcendental intersubjectivity unifies them. Is something which happens in the Havasis songs: the intersubjectivity of the sound unifies the worldlinesses. But why cannot be the subjectivity which does this thing? Because in Husserl's terms the (inter)subjectivity is the subjectivity renovated which is capable to produce the Kantian 'apperception' of the sounds. ${ }^{27}$

Subjectivity was correlated to the cogito. Furthermore the new Husserl's phenomenological method needed to intercalate the cogito with the things, with

\footnotetext{
${ }^{24}$ N.a. The term ilustrates the idea of the expression of the things reflected in conscience. Furthermore, for details we had to consult Dan Zahavi, Subjectivity and Selfhood: Investigating the First-Person Perspective, Massachusetts MIT Press, 2008. He talks about the "structures of time-consciousness", pp. 49-55.

${ }^{25}$ Ibid., p. 57.

${ }^{26}$ Peter Kivy, op. cit., p. 127.

${ }^{27}$ Passim from Imm. Kant in op. cit.
} 
judgements and lived experience of the things. This is the complete manner in which the intentionality functions. But we can not know tat "this sound is beautiful" if we had not had before the lived-experience of a "beautiful sound". To have had the experience of a "beautiful sound", we may had have listened before to other songs during our livesand may have created in us a spiritual universe for our experience connected to my judgement. Once listened a piece, my world becomes connected with the hisotrical-spiritual-world of the symphony, whiches world becomes connected with the world-of-the pianist, whiches world becomes connected with the worldliness of the music, whiches worldliness of the music opens other worlds. It is a fascinating circuit built in fullfill connection ad infinitum. Havasi did not created only a new aesthetic sphere of classicism, but he created a new transcendental-kantian-aesthetic [me] of the elements of the thoughts, and a transcendental-haptic-aesthetic. ${ }^{28}$

\section{Havasi as a hermeneut of the music}

\section{The 'natural-ontic' character of the sound}

Whitehead is well known for his theories about the ontical principles. We want to see how the piano music of Havasi can be related to the ontic character of the Being, so we shall argue with something from Concept of the Nature. He strats his book with a declaration in which says that his preoccupation is focused on the light and souns phenomena: "The doctrines to which I am especially alluding are the theories of light and sound. I have no doubt that the theories had been vaguely floating about before as obvious suggestions of common sense; for nothing in thought is ever completely new. But at that epoch they were systematised and made exact, and their complete consequences were ruthlessly deduced. It is the establishment of this procedure of taking the consequences seriously which marks the real discovery of a theory. Systematic doctrines of light and sound as being something proceeding from the emitting bodies were definitely established, and in particular the connexion of light with colour was laid bare by Newton. The result completely destroyed the simplicity of the 'substance and attribute' theory of perception." ${ }^{29}$

The sounds can be a suggestion of the common sense. He notice also that we have as human being a physical addiction to what produces in us pleasure as sounds, warmth or colors: "Thus colour is not part of the reality of the material object. Similarly for the same reason sounds evaporate from nature." ${ }^{30}$ Furthermore, the sound of Havasi are creating perceptions, but this perception had already affected our sensese. Despire of the Husserl's theories on perceptions, Whitehead tried to unify the sense with perception- "sense-perception has an element that has not been thought ${ }^{\prime \prime 1}$ - because in the natural philosophy, that is a function which plays

\footnotetext{
${ }^{28}$ These terms "transcendental-kantian-aesthetic", and the "transcendental-haptic-aesthetic" were proposed by me to try to unify what Havasi wants to represent for our perceptions.

${ }^{29}$ Whitehead, op. cit., p. 26.

${ }^{30}$ Ibid., p. 43.

${ }^{31}$ Ibid., p. 3.
} 
an ontical act in Being and to be. So, we can be something through the sounds emitted by piano: the tiles of the piano are acting like these sense-perception of Whitehead, because we can force our fingers through our body to feel the affecting dynamism of the sound to my conscience. We can argue in here with an experimental song entitled Elements ${ }^{32}$ which was signed by Ludovico Einaudi. We are in front of the sense-perceptions, and we have to understand them, to take some time to sit down and to think on what the sound are trying to say to us.

Due to the argument provided before that Havasi creates through his hands the sounds of the worldliness and the sounds of the World as a totality, we can say that he is a hermeneut of the music, because he had the capacity to think the sound and its world. In ontical plane, sound can become the equivalent of reason. ${ }^{33}$ Starting with these observations, we can say that Havasi created a new ontology of the sound and re-gaved to the sound his natural 'Becoming', as saying his ontic character. The sound is something which creates, it is something which 'becomes a natural part' in Being. "Also what we really observe in nature, its colours and its sounds and its touches are secondary qualities; in other words, they are not in nature at all but are accidental products of the relations between nature and mind" 34 .

If the sound "becomes",then it is an active agent. But the sound can unify the analytic and synthetic judgements. The sound generates another sound in the hands of the Havasi, the sound generates live experiences. The role of the hands is very important because they play a Daseinic role. The hands are becoming part of this ontology of the music. The judgements about sound are active too, because they create, and even the verb "to create" integrates the action of the verb "to become". The sound gives "to things, to the essents, their weight"35. Why had Heidegger associated the word 'Being' to the word 'weight'? Because we can associate the gravity of the sound with the word sound itself, because we talk in here about a haptic ponderability of the sound which persists in each symphonies of Havasi (as example, "Lacrimosa"). ${ }^{36}$

Peter Kivy says that music gives a sense to our existence, it "can be coherent without being unified, and unified without being coherent" ${ }^{37}$. Despite this, we should say that the contents of the conscience are unified, but what is not unfied, is the material thing with the conscience, because the sound does not meet the conditions to be material (physicalist talking).

Havasi opens a world for the Being and the sound will try to recreate the openings-series of the Being. It is like "to drive-towards-something and to

\footnotetext{
${ }^{32}$ Ludovico Einaudi, “Elements”, in Album Elements, FIMI Italy, 2015, lenght 6:05.

${ }^{33}$ See Martin Heidegger, Being and Time, translated by Joan Stambaugh, State University of New York Press, New York, 1996, p. 30: “[...] logos can mean reason”.

${ }^{34}$ Whitehead, op. cit., p. 141.

${ }^{35}$ Martin Heidegger, Introduction..., 1999, p. 11.

${ }^{36}$ Havasi, "Lacrimosa", Album Drume Piano, Havasi Entertainment Ltd 2013, Budapest, 2013, lenght 4:05.

${ }^{37}$ Peter Kivy, op. cit., p. 203.
} 
penetrate." ${ }^{38}$ The sound penetrates the metaphysic with the condition to put the Being in a perceptive-worldliness, but the main field remains into ontology. Concluding this part, Havasi is a philosopher of the piano sounds.

\section{Conclusion. The hands as the Havasi's trees of the magic forest}

Concluding, we should open a new field of study thanks to Havasi 's music: the philosophy of the haptic relationships between the worldlinesses. This is a noumen (universal) on plural, because due to the personal researches in the field of the folklore and histories of other states, Havasi become a creator of the worldlinesses which communicate between them. Also, Havasi is a creator of a new type of relationships with the 'Other' and the 'Other' in his music is appropriate to each of us. His musical themes are inspired from the life and each theme may have been lived by us once in a lifetime as a storm, a difficult road, a happy man, an in love man, a sad man, a nature with trees and flowers, a Spring in China, the beauty of the Hungarian classic-music, the happiness. All these are coming with the precise purpose to create a 'haptic-mental' worldliness. His ontological 'Becoming' as a pianist-creator unifies them with his ontological 'Becoming' of the piano sounds. The hands are part of this ontological 'Becoming. The perception is part of our body. Our body is a haptic chain between my creation as a pianist and myinner-historical-world full of senses (feelings, perceptions, thoughts, memories etc.). The unity between the hands (as part of the body), mind and worldliness becomes a triadic a priori experience of the lived worldliness.

These observations were the general point of view in a philosophical manner on the novelty in the music of Havasi. He had painted sounds with his hands just to be sure those sounds will never die.

\section{Bibliography:}

Balázs, Havasi, "Daisy's Secret", “The Road”, "Faena", “The Duel”,"“Storm”, "Sunrise”, "Hypnotic", in Album Arena Show 2017, Hungarian Radio Studio no.6, Budapest, 2017.

Balázs, Havasi, "Etude no.1-no.13", in Album Solo Piano Etudes no.1-no.13. Havasi Entertainment Ltd. 2014, Budapest, 2014.

Balázs, Havasi, "Spring. Cultural Bridge Symphony", in Album Symphonic ArenaShow 2014. Budapest, 2014, length 4:56.

Balázs, Havasi, "Lacrimosa", in Album Drume Piano. Havasi Entertainment Ltd., Budapest, 2013, length 4:05.

Balázs, Havasi \& Yunnan Province Art Group, "The Unbending Chinese Tree" on Album Symphonic II, Havasi Entertainment Ltd., Budapest, 2013, length 5:01.

Balázs, Havasi, “Terra Rosa”, in Album Havasi-Red, EMI Music Publishing, Budapest, 2008, length 4:23.

${ }^{38}$ Ibid., p. 19, "diclosure of being” means the unlocking of what forgetfulness of being closes and hides". Cf. with Heidegger, Introducere în metafizică, Romanian edition, translation by Gabriel Liiceanu and Thomas Kleininger, Humanitas Publishing, București, 2011, p. 35. The term in Romanian is "starea de desferecare pe care îl fereacă și îl ascunde". The translation into English is approximately, due to the difficulty of the translation of word 'desferecare'. 
Cortazar, Ernesto, (1) "Beethoven Silence", in Just for You, 2009, length 9:54. Other source is (2) https://www.youtube.com/watch?v=YFD2PPAqNbw, accessed 13 august 2018, length 9:56.

Einaudi, Ludovico, "Elements", in Album Elements, FIMI Italy, 2015, lenght 6:05.

Heidegger, Martin, (1) An Introduction to Metaphysics, translated by Ralph Manheim, M.B. Publishers Private Limited, Delhi, 1999, 2005. (2) Introducere în metafizică, Romanian edition, translation by Gabriel Liiceanu and Thomas Kleininger, Humanitas Publishing, București, 2011.

Heidegger, Martin, Being and Time, translated by Joan Stambaugh, State University of New York Press, New York, 1996.

Huray, Peter le; Day, James, Music and the Aesthetics in the Eighteenth and Early-Nineteenth Century, Cambridge University Press, Cambridge, 1981 [1988].

Kant, Immanuel, The Critique of the Pure Reason, translated and edited by Paul Guyer and Allan W. Wood, Cambridge University Press \& Yale University Press, Pennsylvania \& Yale, 1988.

Kershaw, Baz; Nicholson, Helen, "Introduction: Doing Methods creatively", in book Research Methods in Theatre and Performance, edited by Baz Kershaw and Helen Nicholson, Edinburgh University Press, Edinburgh, 1988, pp. I-XVI.

Kivy, Peter, New Essays on Musical Understanding, Clarendon Press, Oxford, 2001.

Lippman, Arthur E., "Symbolism in Music", in The Musical Quarterly 39 (4), 554. Oxford, Oxford University Press, 1953: 554-575.

Papu, Edgar, Despre stiluri (On Styles), original edition in Romanian, Eminescu Publishing, Bucharest, 1986.

Sepp, Hans Reiner; Embree Lester (ed.), Handbook of Phenomenological Aesthetics, Springer, Charles University Prague \& Florida Atlantic University, 2010.

Vianu, Tudor, Studii de filozofia culturii, (Studies in Philosophy of Culture), Romanian edition, Eminescu Publishing, Bucharest, 1982.

Whitehead, Alfred North, The Concept of Nature, Cambridge University Press, Cambridge, 1920.

Ziolkowski, Theodore, Classicism of the Twenties. Art, Musice Literature, Chicago Press, Chicago, 2015. 